\title{
Expression of Rho GDla in rat osteoblasts intermittently exposed to parathyroid hormone in vitro and in vivo
}

\author{
Zu-feng SUN ${ }^{1, \#}$, Hui JIANG ${ }^{2, \#}$, Zheng-qin YE ${ }^{1}$, Bing JIA ${ }^{1}$, Xiao-le ZHANG ${ }^{1}$, Ke-qin ZHANG ${ }^{1, *}$ \\ ${ }^{1}$ Department of Endocrinology, the First Affiliated Hospital of Nanjing Medical University, Nanjing 210029 , China; ${ }^{2}$ Department of \\ Endocrinology, the First People's Hospital of Zhenjiang, Zhenjiang 212001, China
}

\begin{abstract}
Aim: To investigate the mechanism of the bone-forming effects of intermittent parathyroid hormone (PTH) administration and to search for novel molecules of bone anabolism via the PTH signaling pathway.

Methods: Primary cultures of rat osteoblasts (ROBs) were divided into an intermittent PTH-treated group (Itm) and a control group (Ctr). Imitating the pharmacokinetics of intermittent PTH administration in vivo, the ROBs in the Itm group were exposed to PTH for $6 \mathrm{~h}$ in a 24-h incubation cycle, and the ROBs in the Ctr group were exposed to vehicle for the entire incubation cycle. The cells were collected at $6 \mathrm{~h}$ and $24 \mathrm{~h}$ of the final cycle, and the proteins in the Itm and Ctr groups were analyzed by two-dimensional electrophoresis (2-DE) coupled with peptide mass fingerprinting and matrix assisted laser desorption/ionization time-of-flight mass spectrometry (MALDITOF-MS) to detect proteins that were differentially expressed. The proteins with the most significant changes in vitro were validated by immunohistochemistry $(\mathrm{IHC})$ in a rat model.

Results: The proteomics analysis indicated that a total of 26 proteins were up- or down-regulated in the Itm group compared with the Ctr group at $6 \mathrm{~h}$ and $24 \mathrm{~h}$; among these, 15 proteins were successfully identified. These proteins mainly belong to the cytoskeleton and molecular chaperone protein families, and most of these have anti-apoptotic effects in various cells. Rho GDP-dissociation inhibitor $\alpha$ (RhoGDI $\alpha$ ) and vimentin were the most significantly changed proteins. Further studies by IHC showed that the expression of RhoGDI $\alpha$ in ROBs was significantly higher in PTH-treated sham-operated rats than in vehicle-treated sham-operated rats, but the difference was not significant between PTH-treated and vehicle-treated OVX rats. Vimentin expression was not changed in either PTH-treated shamoperated rats or PTH-treated OVX rats.

Conclusion: Our research suggests that intermittent PTH treatment induces changes in expression of many proteins in ROBs in vitro, and it results in RhoGDI $\alpha$ up-regulation in ROBs both in vitro and in vivo when estrogen is present. This up-regulation of RhoGDl $\alpha$ may be one of the mechanisms underlying the synergistic bone-forming effect of PTH and estrogen.
\end{abstract}

Keywords: parathyroid hormone; Rho GDP-dissociation inhibitor $\alpha$; osteoblast; immunohistochemistry; proteomics

Acta Pharmacologica Sinica (2009) 30: 1001-1007; doi: 10.1038/aps.2009.60

\section{Introduction}

The treatment of osteoporosis at the present time mainly depends on antiresorptive agents such as bisphosphonates (BPs) and calcitonin, as well as estrogen. However, these drugs only have moderate effects on increasing bone mass. There is no satisfactory drug that considerably increases bone mass for severe osteoporosis. PTH is a major osteotropic factor that plays a critical role in calcium homeostasis and in regulating bone turnover. PTH possesses bi-directional actions,

\footnotetext{
* To whom correspondence should be addressed.

\# The two authors contributed equally to this work.

E-mail keqzhang2007@126.com

Received 2009-02-12 Accepted 2009-04-14
}

ie, it is bone-catabolic and bone-anabolic. Many experiments have shown that continuous exposure to PTH decreases bone mass by stimulating a net increase in bone resorption, whereas intermittent administration of PTH can increase bone mass ${ }^{[1-4]}$. The mechanism involved in osteogenesis of intermittent PTH administration is not clear. Osteoblasts play a central role in PTH-mediated osteogenesis in vivo, and even the effect of PTH on osteoclasts is mediated by osteoblasts; therefore, research designed to determine the effects of PTH on osteoblasts is an important approach for studying the anabolic mechanisms of PTH and for searching for new therapeutic strategies to the treatment of osteoporosis.

A previous DNA microarray analysis reported changes in the gene expression profile of an osteoblastic cell line (UMR 
106-01) when the cells were treated with PTH. A total of 125 known genes and 30 unknown expressed sequence tags (ESTs) were found to have at least a twofold change in expression after PTH treatment for 4, 12, and $24 \mathrm{~h}^{[5]}$; however, quantitative mRNA data does not necessarily correlate well with protein expression levels ${ }^{[6]}$. A two-dimensional electrophoresis (2-DE)-based proteomics approach provides a powerful tool to simultaneously analyze changes in protein levels in tissues and cells ${ }^{[7]}$, and it should help us uncover the anabolic mechanisms of PTH. Recently, using comparative proteomics, some researchers identified candidate biomarkers to distinguish osteosarcoma cells from normal osteoblastic cells. In our study, proteomics technologies were applied to identify PTH-regulated proteins in osteoblasts with intermittent PTH treatment (this cell model is anabolic for bone as documented previously in our laboratory $\left.{ }^{[8]}\right)$. We found tens of proteins that were increased or decreased in osteoblasts intermittently exposed to PTH; among those that changed, the expression levels of RhoGDIa, GRP78 and vimentin were up-regulated to the greatest extent (around 10-fold). Furthermore, RhoGDIa and vimentin content were also increased in the secreted protein spectrum (also called "secretome") of the same cell model ${ }^{[9]}$. To validate the in vitro results of RhoGDIa and vimentin, recombinant human PTH was intermittently (once daily) injected into rats, and immunohistochemistry was used to observe the in vivo changes of RhoGDIa and vimentin in rat bone osteoblasts.

\section{Materials and methods}

\section{Cell model of intermittent PTH treatment}

Primary cultures of ROBs were obtained using an enzyme digestion method described previously ${ }^{[10]}$. Cells were maintained in DMEM (Gibco, Carlsbad, CA, USA) containing 10\% fetal bovine serum (FBS, Hyclone, Logan, USA). PTH (1-34) (P3796, Sigma, St Louis, USA ) stock solution $(5 \mu \mathrm{g} / \mathrm{mL})$ was prepared by dissolving PTH in a $20 \mathrm{~mL} 0.1 \%$ HAc solution containing $0.1 \%$ BSA. The cultured ROBs were divided into a PTH-treated group (Itm) and a control group (Ctr). Itm groups were cultured in PTH-containing $(50 \mathrm{ng} / \mathrm{mL})$ medium for the first $6 \mathrm{~h}$ and in the vehicle medium (containing 0.1\% HAc) for the subsequent $18 \mathrm{~h}$ in a $24-\mathrm{h}$ incubation cycle. The control groups were cultured in vehicle medium all the time. There were three $24-\mathrm{h}$ cycles during the study. In the third cycle, the cells were collected at $6 \mathrm{~h}$ and $24 \mathrm{~h}$.

\section{Protein extraction, 2-DE and protein identification}

Osteoblasts were lysed in lysis buffer containing $7 \mathrm{~mol} / \mathrm{L}$ urea, $2 \mathrm{~mol} / \mathrm{L}$ thiourea, $4 \%$ CHAPS, $65 \mathrm{mmol} / \mathrm{L}$ DTT, $40 \mathrm{mmol} / \mathrm{L}$ Tris and 2\% (pH 3-10) IPG (immobilized PH gradient) buffer (Amersham Biosciences, Uppsala, Sweden). Samples were then kept on ice and sonicated in 5 cycles each consisting of a 3-s sonication followed by a 30-s break and, finally, held for $1 \mathrm{~h}$ at room temperature with occasional vortex mixing. After centrifugation at $40000 \times \mathrm{g}$ for $1 \mathrm{~h}$ at $4{ }^{\circ} \mathrm{C}$, protein concentrations of the supernatant were measured by the Bradford assay ${ }^{[11]}$. Proteins $(120 \mu \mathrm{g})$ were applied to IPG (immobilized
pH gradient) strips ( $24 \mathrm{~cm}, \mathrm{PH} 4-7, \mathrm{NL}$, Amersham Biosciences) using a passive rehydration method. After $12 \mathrm{~h}$ of rehydration, isoelectric focusing (IEF) was performed as follows: 500 $\mathrm{V}$ for $1 \mathrm{~h}, 1000 \mathrm{~V}$ for $1 \mathrm{~h}$, and then at $8000 \mathrm{~V}$ up to total 80000 $\mathrm{V} \cdot \mathrm{h}$. Once IEF was completed, the strips were equilibrated in equilibration buffer $(0.375 \mathrm{~mol} / \mathrm{L}$ Tris- $\mathrm{HCl}, \mathrm{pH} 8.8,6 \mathrm{~mol} / \mathrm{L}$ urea, 20\% glycerol, 2\% SDS, and 1\% DTT) for $15 \mathrm{~min}$, followed by the same buffer containing $2.5 \%$ iodoacetamide instead of DTT for another $15 \mathrm{~min}$. The second dimension was performed using an Ettan-Dalt II system (Amersham Pharmacia, Uppsala, Sweden) with $12.5 \%$ SDS-PAGE at $2 \mathrm{~W} /$ gel for $1 \mathrm{~h}, 5$ $\mathrm{W} /$ gel for $30 \mathrm{~min}$ and $15 \mathrm{~W} /$ gel for $10 \mathrm{~h}$, until the bromophenol blue front had reached the bottom of the gel. Samples were run for three independent cell culture experiments. Proteins were visualized by silver staining of the gels. The images were scanned with ImageScanner (Amersham Biosciences, Uppsala, Sweden), and image analysis was carried out using ImageMaster 2D Elite (Version 2.0) software (Amersham Biosciences, Uppsala, Sweden). The differential expression protein spots between the two groups were selected and analyzed by matrix-assisted laser desorption ionization time-of-flight mass spectrometry (MALDI/TOF MS). Peptide masses generated from the MALDI/TOF MS analysis were used for protein identification by peptide mass fingerprinting (PMF). The data obtained from PMF were retrieved using the search algorithm MASCOT against the Expasy protein sequence database. The proteins were identified using a number of criteria, including $\mathrm{pI}, M_{\mathrm{W}}$, sequence coverage, and score.

\section{Animal models}

Four-week-old virgin female specific pathogen-free (SPF) Sprague Dawley rats weighing $100 \pm 10 \mathrm{~g}$ (ShangHai SLAC Laboratory Animal Co Ltd SCXK 2003-0003) were housed at a SPF animal facility at Laboratory Animals of Nanjing Medical University and had ad libitum access to water and commercial standard food. After 1 week of acclimatization to their new environment, the rats were either ovariectomized (OVX) or sham-operated. OVX or sham-operated rats were randomly divided into 4 groups (Figure 1). Three weeks following sur-

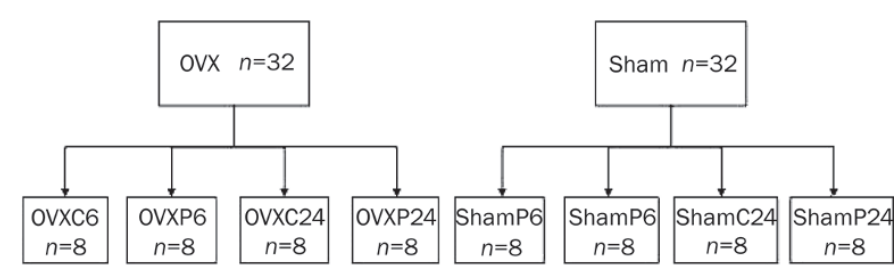

Figure 1. A total of 64 female SD rats were separated into eight groups. On average, each group consisted of 8 rats. OVXC (shamc) represents OVX (sham-operated) injected with vehicle (0.01\% HAc) and OVXP (ShamP) means OVX (sham-operated) injected with rhPTH (1-34). Shamc6 (C24) means the sham-operated rats will be sacrificed at $6 \mathrm{~h}$ or $24 \mathrm{~h}$ postinjection of HAc on the last day. ShamP6 (P24) means the sham-operated rats will be sacrificed at $6 \mathrm{~h}$ or $24 \mathrm{~h}$ post-injection of PTH on the last day. OVXC6 (C24) and OVXP6 (P24) represent the same meaning and the difference is OVX rats was used to replace sham-operated rats. 
gery, animals were injected subcutaneously with rhPTH (1-34) (Lilly, USA) $40 \mu \mathrm{g} \cdot \mathrm{kg}^{-1} \cdot \mathrm{d}^{-1}$ or with vehicle $(0.01 \%$ HAc) for 7 days. At $6 \mathrm{~h}$ and $24 \mathrm{~h}$ post-injection of PTH or vehicle on the last day, each group of rats was sacrificed. Tibias cleaned of soft tissue were obtained and fixed in cold $4 \%$ paraformaldehyde. The bones were then decalcified in $10 \%$ EDTA at $\mathrm{pH}$ 7.2.

\section{Immunohistochemistry}

Immunohistochemical analysis was performed by the EnVision $+{ }^{\mathrm{TM}}$ system (Dako Cytomation, CA, USA) to determine the protein expression of RhoGDIa and vimentin in osteoblasts of rat tibia. The procedure can be described as follows. Consecutive paraffin wax embedded tissue sections (5 $\mu \mathrm{m})$ were de-waxed and rehydrated through graded alcohol rinses. Antigen retrieval was performed by incubating the slides in $0.1 \% \mathrm{CaCl}_{2}$ containing $0.1 \%$ trypsin for $50 \mathrm{~min}$. Endogenous peroxidase activity was quenched by incubating the slides in 6\% hydrogen peroxide for $20 \mathrm{~min}$, followed by washing in PBS containing 0.2\% Tween 20 (PBST) three times; the sections were incubated at $4^{\circ} \mathrm{C}$ overnight with the normal goat serum and were rinsed with PBST and incubated at $4{ }^{\circ} \mathrm{C}$ overnight with the primary mouse monoclonal antibody against RhoGDIa (diluted 1:50, sc-13120, Santa Cruz Biotechnology, CA, USA), mouse monoclonal antibody against vimentin (diluted 1:25, sc-32322, Santa Cruz Biotechnology, CA, USA) individually, followed by washing with PBST. For the visualization of RhoGDIa and vimentin, Envision+/HRP was applied to the sections for $2 \mathrm{~h}$ at room temperature, and diaminobenzidine hydrochloride (DAB) was used. These sections were counterstained with Meyer's hematoxylin. In order to prove the specificity of the immunoreaction, a negative control was carried out by omitting the primary antibody and using PBS instead. In order to exclude non-specific binding of the antibodies to unrelated antigens, a pre-adsorption control was run for RhoGDIa by using an antibody/peptide mixture containing a twofold excess of blocking peptide (sc-13120p, Santa Cruz Biotechnology, CA, USA). For RhoGDIa and vimentin, cytoplasmic staining was considered to be positive expression. Six representative sections were chosen in each group containing 8 rats. In each section, the number of positive and negative osteoblasts was counted in five high-power fields $(\times 400)$ near the growth plate of the tibia using ImageProPlus 5.0 (Media cybernetics, Silver Spring, MD, USA). The proportion of positively stained cells (positive osteoblasts/ total osteoblasts) was counted in each field, and then the average proportion of positive osteoblasts was counted in each section. Finally, the average proportion of positive osteoblasts for each group was compared.

\section{Statistical analysis}

The average proportion of positive osteoblasts was presented as mean $\pm S D$. Comparisons between groups of data were made using an unpaired $t$-test (GraphPad InStat for Windows Version 3.0; GraphPad Software Inc). $P<0.05$ was considered statistically significant.

\section{Results}

\section{Results of 2-DE}

To ensure repeatability, the experiments were repeated three times. Only those spots that changed consistently and significantly (more than twofold) were defined as differentially expressed proteins. Cropped images from 2-D gels demonstrating the differential expression of selected proteins were shown in Figure 2 and Figure 3. A total of 26 spots were identified as differentially expressed, and of those, 7 proteins were down-regulated in the Itm group at $6 \mathrm{~h}$ (Figure 2) whereas 14 proteins were up-regulated and 5 proteins were downregulated in the Itm group at $24 \mathrm{~h}$ (Figure 3 ) compared with the control group.

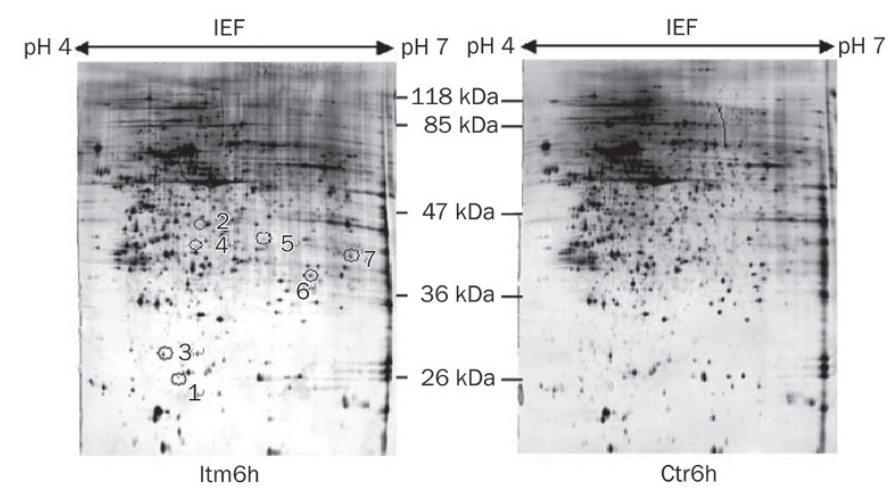

Figure 2. Silver stained 2-DE maps of proteins that were differentially expressed in Itm6h and Ctr6h groups. Spots of proteins that were differentially expressed are labeled with numbers. Spots 1-7 represent the down-regulated proteins in the Itm6h group. Only down-regulated proteins can be seen at Itm6h.

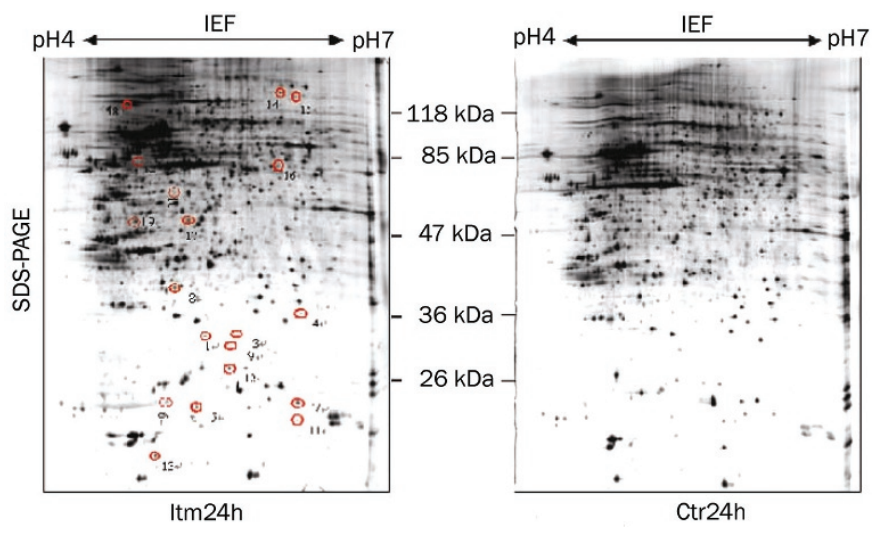

Figure 3. Silver stained 2-DE maps of proteins that were differentially expressed in the Itm24h and Ctr24h groups. Spots of proteins that were differentially expressed are labeled with numbers. Spots 1-13 and 19 represent the up-regulated proteins, and spots 14-18 represent the down-regulated proteins in the Itm24h group compared with the Ctr24h group. 


\section{Protein identification}

Differentially expressed protein spots (spots 1-5 in Itm6h and spots 1-10, 12, 14-15, 19 in Itm24h) were selected and subjected to mass spectrometry analysis. We finally identified 4 down-regulated proteins (Table 1) and 11 up-regulated proteins (Table 2). The properties of 2 proteins (spots 5 and 12) are unknown in the protein database. Two other proteins (Spots 14 and 15), which were down-regulated in Itm24h, were not successfully detected because of the low content of protein.

\section{IHC analysis of RhoGDI $\alpha$}

The expression of RhoGDIa and vimentin in ROBs increased almost 10 -fold in the Itm 24 h group compared with the control group in vitro. IHC was performed to confirm the results obtained by proteomics technologies. Representative immunohistological staining of RhoGDIa in rat tibia was shown in Figure 4. The results of comparing each group's average proportion of positive osteoblasts are described in Figure 5. In the sham groups, the expression of RhoGDIa in PTHtreated rats was higher than in controls (ShamP6 vs ShamC6, $81.18 \% \pm 4.7 \%$ vs $69.93 \% \pm 8.52 \%, P=0.018$; ShamP24 vs ShamC24, $82.09 \% \pm 3.94 \%$ vs $69.44 \% \pm 6.46 \%, P=0.002)$. In the OVX groups, there were no differences between PTH-treated rats and controls (OVXP6 vs OVXC6, $66.55 \% \pm 6.27 \%$ vs $59.46 \% \pm 7.72 \%$,
$P=0.111$; OVXP24 vs OVXC24, $75.28 \% \pm 9.27 \%$ vs $68.95 \pm 10.07 \%$, $P=0.284$ ). No positive staining was observed in the negative control group (Figure 4A) and the pre-adsorption control group (Figure 4B). As to vimentin, we did not see any differences between the PTH-treated and vehicle-treated Sham/ OVX rats (data not shown).

\section{Discussion}

This study used a proteomics approach to identify PTH-regulated proteins within ROBs intermittently treated with PTH. This model of intermittent PTH stimulation of ROBs imitates the pharmacokinetics of PTH in vivo, and in this model, PTH can directly stimulate the osteogenesis of ROBs as it does in vivo; therefore, this model is more reasonable than previously used cell models of continuous PTH stimulation, which suppressed the osteogenesis of $\operatorname{ROBs}^{[12,13]}$. Using 2-DE on cell lysates, we successfully identified 4 down-regulated proteins in the Itm6h group and 11 up-regulated proteins in the Itm $24 \mathrm{~h}$ group compared with controls. Among them, F-actin capping protein, beta-actin, and vimentin belong to the family of cellular structural proteins that play an important role in maintaining cell morphology, in stabilizing the cell membrane, and in regulating cell apoptosis ${ }^{[14,15]}$. ERP29, PDI-precursor, GRP78 precursor, GrpE (GrpE-like 1 and GrpE protein homolog 1), and RhoGDIa were up-regulated in the Itm 24 h group and

Table 1. Identification of differentially expressed proteins (6 h).

\begin{tabular}{llcrcll}
\hline $\begin{array}{c}\text { Spot } \\
\text { No }\end{array}$ & $\begin{array}{c}\text { Accession } \\
\text { No }\end{array}$ & $\begin{array}{c}\text { Sequence } \\
\text { coverage }\end{array}$ & Score & $\begin{array}{c}\text { Down-Regulated } \\
\text { folds }\end{array}$ & $\begin{array}{c}\text { Theoretical } \\
\text { Pl/molecular } \\
\text { weight (kDa) }\end{array}$ & Protein name \\
\hline 1 & Q5XI32 & $27 \%$ & 104 & $2.54 \downarrow$ & $5.69 / 30.9$ & F-actin capping protein beta subunit \\
2 & Q68FT7 & $7 \%$ & 55 & $2.09 \downarrow$ & $6.63 / 66.3$ & Phenylalanine-tRN Asynthetase-like subunit \\
3 & Q499R7 & $17 \%$ & 57 & $2.20 \downarrow$ & $6.42 / 38.2$ & Pp protein \\
4 & Q7TNI4 & $23 \%$ & 52 & $2.18 \downarrow$ & $9.19 / 27.1$ & IL-22R-alpha-2 \\
5 & Q5IODI & $25 \%$ & 84 & $4.37 \downarrow$ & $5.11 / 33.5$ & Hypothetical \\
\hline
\end{tabular}

Table 2. Identification of differentially expressed proteins (24 h).

\begin{tabular}{cccccll}
\hline $\begin{array}{c}\text { Spot } \\
\text { No }\end{array}$ & $\begin{array}{c}\text { Accession } \\
\text { No }\end{array}$ & $\begin{array}{c}\text { Sequence } \\
\text { coverage }\end{array}$ & Score & $\begin{array}{c}\text { Up-Regulated } \\
\text { folds }\end{array}$ & $\begin{array}{c}\text { Theoretical } \\
\text { Pl/molecular } \\
\text { weight (kDa) }\end{array}$ & Protein name \\
\hline 1 & P60711 & $20 \%$ & 98 & $2.02 \uparrow$ & $5.29 / 42.0$ & Beta-actin \\
2 & P310001 & $71 \%$ & 409 & $10.12 \uparrow$ & $5.06 / 53.6$ & Vimentin \\
3 & P06761 & $13 \%$ & 60 & $11.23 \uparrow$ & $5.07 / 72.5$ & 78 kDa glucose-regulated protein precursor (GRP 78) \\
4 & Q4QRA3 & $13 \%$ & 59 & $2.77 \uparrow$ & $8.57 / 24.5$ & GrpE-like 1 \\
5 & P97576 & $14 \%$ & 53 & $2.09 \uparrow$ & $8.57 / 24.5$ & GrpE protein homolog 1 \\
6 & P04785 & $8 \%$ & 55 & $4.70 \uparrow$ & $4.82 / 57.3$ & Protein disulfide-isomerase precursor (PDI) \\
7 & P52555 & $36 \%$ & 94 & $3.27 \uparrow$ & $6.23 / 28.6$ & Endoplasmic reticuhum protein precursor (ERp29) \\
8 & Q5XI73 & $37 \%$ & 93 & $9.89 \uparrow$ & $5.12 / 23.5$ & Rho GDP dissociation inhibitor (GDI) alpha \\
9 & O88767 & $46 \%$ & 146 & $2.77 \uparrow$ & $6.32 / 20.2$ & Protein DJ-1 \\
10 & Q5RKH & $18 \%$ & 89 & $2.34 \uparrow$ & $5.24 / 42.8$ & Galactokinase 1 \\
12 & Q5I0DI & $15 \%$ & 66 & $2.37 \uparrow$ & $5.11 / 33.5$ & Hypothetical \\
19 & PI5473 & $28 \%$ & 50 & $2.00 \uparrow$ & $8.68 / 32.7$ & Insulin-like growth factor binding protein 3 precursor (IGFBP-3) \\
\hline
\end{tabular}



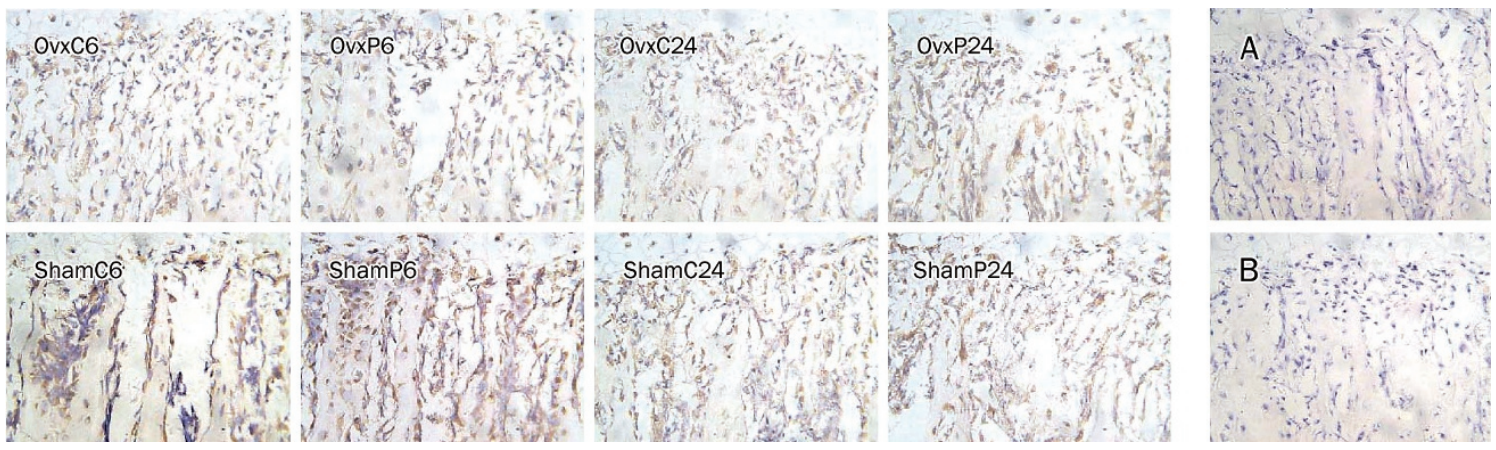

Figure 4. Representative immunohistological staining of RhoGDI $\alpha$ under the growth plate of the rat tibia is shown. Positive osteoblasts were observed in OVX or sham-operated rats which were either vehicle-treated or PTH-treated. Image analysis software (Image-ProPlus 5.0) was used to count the proportion of positive osteoblasts in each field. A total of five fields were selected in each slide, and these pictures represented only one field, respectively. (A) A negative control was performed without the addition of the primary antibody, and it represents background staining. (B) A preadsorption control performed using an antibody/peptide mixture was also negative for RhoGDl $\alpha$. Magnification $\times 400$.
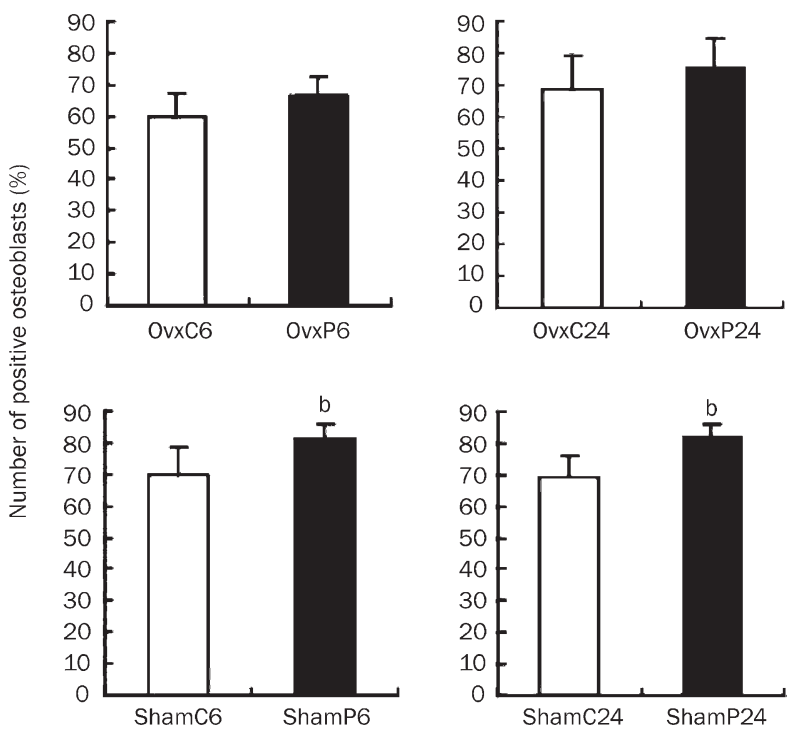

Figure 5. The percentage of positive osteoblasts in each group. $n=6$ per group. Data were presented as mean \pm SD. The data for sham groups (ShamP6 vs Shamc6; ShamP24 vs ShamC24) and OVX groups (OvxP6 vs OvxC6; OvxP24 vs OvxC24) were compared. ${ }^{\mathrm{b}} \mathrm{P}<0.05$ compared with each control.

belong to the family of molecular chaperone proteins, which plays a key role in the processes of protein biosynthesis, signal transduction, immunoregulation, and apoptosis. IGFBP3 , a member of the IGFBP family, promotes bone metabolism when it binds to IGF- ${ }^{[16]}$, but over-expression of IGFBP-3 can inhibit osteogenesis ${ }^{[17]}$. As for IL-22R-alpha-2, phenylalaninetRNA synthetase-like subunit, $\mathrm{Pp}$ protein, and Galactokinase 1 , we did not find some significant references for these proteins related to bone metabolism. The roles played by these molecules in PTH-induced osteogenesis are still unknown, and their fluctuations within osteoblasts represent novel findings that deserve further investigation. In this study, there is no succession of categories of differentially expressed proteins from $6 \mathrm{~h}$ to $24 \mathrm{~h}$. The reason may be as follows: (1) accretion rate of cellular proteins is fast; (2) the processes stimulated by PTH not only occur during incubation with PTH, but also occur for some time after the PTH has been removed, and the delayed effect of PTH after removal of PTH may be more important for the anabolic effect because continuous exposure to PTH inhibits the function of ROBs. This view was also supported by our previous research ${ }^{[8]}$. We temporarily called this effect of PTH the "delayed effect of trigger".

The intermittent treatment of PTH can result in a dramatic increase of RhoGDIa and vimentin in ROBs in vitro, but the overexpression of vimentin was not observed in ROBs in vivo; therefore, the in vitro result was inconsistent with the in vivo result. However, as for RhoGDIa, we obtained consistent results in vitro and in vivo, ie, intermittent stimulation of $\mathrm{PTH}$ promoted overexpression of RhoGDIa, not only in ROBs in vitro, but also in sham-operated ROBs in vivo. It is important to note that intermittent PTH had no stimulation effect on the expression of RhoGDIa in ovariectomized ROBs. This result suggests that intermittent PTH stimulates overexpression of RhoGDIa only in the presence of estrogen (enough estrogen existed both in the medium of ROBs with fetal bovine serum and sham-operated rats), and that RhoGDIa may not be involved in the treatment of osteoporosis in OVX rats using PTH.

RhoGDIa, a cytoplasmic protein originally identified as a negative regulator of the Rho family of GTPases, is ubiquitously expressed in cells and tissues ${ }^{[18,19]}$. The Rho family of GTPases, which include Rac1, RhoA, and Cdc42, are well known for their ability to regulate actin cytoskeleton remodeling, thereby promoting changes in cell morphology, adhesion, and motility ${ }^{[20]}$. RhoGDIa, by binding to Rho GTPases, inhibits their activation. Transgenic mice lacking RhoGDIa had impaired development of the kidneys and reproductive $\operatorname{organs}^{[21]}$. Moreover, RhoGDIa also plays a significant role in the development of human cancers ${ }^{[22,23]}$. What is the effect of RhoGDIa on bone metabolism? RhoGDIa can increase estrogen receptor (ER) transactivation by antagonizing Rho 
function $^{[24]}$, while ER is crucial for bone mass maintenance in both human ${ }^{[25]}$ and mouse ${ }^{[26,27]}$. The biological effects of estrogen are mediated by ER, and ERa is required for estrogen to stimulate cancellous bone formation in long bones of male and female mice ${ }^{[28]}$. Therefore, the elevation of RhoGDIa is helpful for bone synthesis, and our results can at least partly explain why combined therapy with PTH and estrogen in ovariectomized rats ${ }^{[29]}$ and in osteoporotic patients ${ }^{[30]}$ could be more efficacious at increasing bone mass than PTH or estrogen alone. Moreover, RhoGDIa is an antiapoptotic molecule $\mathrm{e}^{[31]}$, and it may play an important role in inhibiting the apoptosis of osteoblasts. Hence, RhoGDIa may be involved in PTHinduced osteogenesis by increasing ER transactivation and its antiapoptotic action.

In summary, this paper is the first report that intermittent administration of PTH significantly increases the expression level of RhoGDIa in ROBs in vitro and in vivo if estrogen is present. This result supports the combination therapy of PTH and estrogen in the treatment of osteoporosis. In addition to RhoGDIa, other differentially expressed proteins identified in this study also represent novel findings that deserve further analysis. With more in-depth research on these proteins, we will obtain some new targets to treat metabolic bone diseases such as osteoporosis.

\section{Acknowledgments}

This project was supported by the Research Foundation for the Returned Overseas Scholars of the Ministry of Education of China and of the Ministry of Personnel of China. We thank the Central Laboratory of Nanjing Medical University for technical support for the MS/MS analysis.

\section{Author contribution}

Ke-qin ZHANG designed the research; Zu-feng SUN and Hui JIANG performed the research; Zu-feng SUN analyzed the data and wrote the paper. Zheng-qin YE, Bing JIA, and Xiao-le ZHANG helped us complete animal experiment.

\section{References}

1 Misof BM, Roschger P, Cosman F, Kurland ES, Tesch W, Messmer $P$, et al. Effects of intermittent parathyroid hormone administration on bone mineralization density in iliac crest biopsies from patients with osteoporosis: a paired study before and after treatment. J Clin Endocrinol Metab 2003; 88: 1150-6.

2 Gabet Y, Kohavi D, Muller R, Chorev M, Bab I. Intermittently administered parathyroid hormone (1-34) reverses bone loss and structural impairment in orchiectomized adult rats. Osteoporos Int 2005; 16 : 1436-43.

3 Sato M, Westmore M, Ma YL, Schmidt A, Zeng QQ, Glass EV, et al. Teriparatide $[\mathrm{PTH}(1-34)]$ strengthens the proximal femur of ovariectomized nonhuman primates despite increasing porosity. J Bone Miner Res 2004; 19: 623-9.

4 Hock JM, Gera I. Effects of continuous and intermittent administration and inhibition of resorption on the anabolic response of bone to parathyroid hormone. J Bone Miner Res 1992; 7: 65-72.

5 Qin L, Qiu P, Wang LQ, Li X, Swarthout JH, Soteropoulou P, et al. Gene expression profiles and transcription factors involved in parathyroid hormone signaling in osteoblasts revealed by microarray and bioinformatics. J Biol chem 2003; 278: 19723-31.

6 Gygi SP, Rochon Y, Robert Franza B, Aebersold R. Correlation between protein and mRNA abundance in yeast. Mol Cell Biol 1999; 19: 1720-30.

7 Guo QC, Shen JN, Jin S, Wang J, Huang G, Zhang L, et al. Comparative proteomic analysis of human osteosarcoma and SV40-immortalized normal osteoblastic cell lines. Acta Pharmacol Sin 2007; 28: 850-8.

8 Zhang KQ, Chen JW, Wang ML, Wang C, Li G, Zheng Z, et al. The expression of insulin-like growth factor-I mRNA and polypeptide in rat osteoblasts with exposure to parathyroid hormone. Chin Med J (Engl) 2003; 116: 1916-22.

9 Jiang LL, Jiang $\mathrm{H}$, Liu CP, Zhang KQ. The secretome profile in rat osteoblasts intermittently exposed to parathyroid hormone. Chin J Osteoporosis Bone Miner Res 2008; 1: 53-8.

10 Mcsheehy PM, Chambers TJ. Osteoblastic cells mediate osteoclastic responsiveness to parathyroid hormone. J Endocrinol 1986; 118: 824-8.

11 Bradford MM. A rapid and sensitive method for the quantitation of microgram quantities of protein utilizing the principle of protein dye binding. Anal Biochem 1976; 72: 248-54.

12 Schiller PC, D'Ippolito G, Roos BA, Howard GA. Anabolic or catabolic responses of MC3T3-E1 osteoblastic cells to parathyroid hormone depend on time and duration of treatment. J Bone Miner Res 1999; 14: 1504-12.

$13 \mathrm{Kroll} \mathrm{MH}$. Parathyroid hormone temporal effects on bone formation and resorption. Bull Math Biol 2000; 62: 163-88.

14 Gourlay CW, Ayscough KR. The actin cytoskeleton: a key regulator of apoptosis and ageing? Nat Rev Mol Cell Biol 2005; 6: 583-9.

15 Morishima N. Changes in unclear morphology during apoptosis correlate with vimentin cleavage by different caspases located either upstream or downstream of $\mathrm{Bcl}-2$ action. Genes to Cell 1999; 4: 401-14.

16 Tanaka H, Moriwake T, Matsuoka Y, Nakamura T, Seino Y. Potential role of rhIGF-I/IGFBP-3 in maintaining skeletal mass in space. Bone 1998; 22: 145S-147S.

17 Silha JV, Mishra S, Rosen CJ, Beamer WG, Turner RT, Powell DR, et al. Perturbations in bone formation and resorption in insulin-like growth factor binding protein-3 transgenic mice. J Bone Miner Res 2003; 18 : 1834-41.

18 Fukumoto Y, Kaibuchi K, Hori Y, Fujioka H, Araki S, Ueda T, et al. Molcular cloning characterization of a novel type of regulatory protein (GDI) for the rho proteins, ras p21-like small GTP-binding proteins. Oncogene 1990; 5: 1321-8.

19 Leonard D, Hart MJ, Platko JV, Eva A, Henzel W, Evans T, et al. The identification and characterization of a GDP-dissociation inhibitor (GDI) for the CDC42Hs protein. J Biol Chem 1992; 267: 22860-8.

20 Hall A. Rho GTPase and the actin cytoskeleton. Science 1998; 279: 509-14.

21 Togawa A, Miyoshi J, Ishizaki H, Tanaka M, Takakura A, Nishioka H, et al. Progressive impairment of kidneys and reproductive organs in mice lacking RhoGDI. Oncogene 1999; 18: 5373-80.

22 Jones MB, Krutzsch H, Shu H, Zhao YM, Liotta LA, Kohn EC, et al. Proteomic analysis and identification of new biomarkers and therapeutic targets for invasive ovarian cancer. Proteomics 2002; 2: 76-84.

23 Fritz G, Just I, Kaina B. Rho GTPases are over-expressed in human tumors. Int J Cancer 1999; 81: 682-7.

24 Su LF, Knoblauch R, Garabedian MJ. Rho GTPases as modulators of the estrogen receptor transcriptional response. J Biol Chem 2001; 
276: 3231-7.

25 Smith EP, Boyd J, Frank GR, Takabashi H, Cohen RM, Speeker B, et al. Estrogen resistance caused by a mutation in the estrogen-receptor gene in a man. N Engl J Med 1994; 331: 1056-61.

26 Korach KS. Insights from the study of animals lacking functional estrogen receptor. Science 1994; 266: 1524-7.

27 Lee KCL, Jessop H, Suswillo R, Zaman G, Lanyon LE. The adaptive response of bone to mechanical loading in female transgenic mice is deficient in the absence of estrogen receptor- $\alpha$ and $-\beta$. J Endocrinol 2004; 182: 193-201.

28 Mcdougall KE, Perry MJ, Gibson RL, Colley SM, Korach KS, Tobias JH. Estrogen receptor- $\alpha$ dependency of estrogen's stimulatory action on cancellous bone formation in male mice. J Endocrinol 2003; 144:
1994-9.

29 Shen V, Birchman R, Xu R, Otter M, Wu D, Lindsay R, Dempster DW. Effects of reciprocal treatment with estrogen and estrogen plus parathyroid hormone on bone structure and strength in ovariectomized rats. J Clin Invest 1995; 96: 2331-8.

30 Bradbeer JN, Arlot ME, Meunier PJ, Reeve J. Treatment of osteoporosis with parathyroid peptide (hPTH 1-34) and oestrogen: increase in volumetric density of iliac cancellous bone may depend on reduced trabecular spacing as well as increased thickness of packets of newly formed bone. J Clin Endocrinol 1992; 37: 282-9.

31 Zhang BL, Zhang YQ, Dagher MC, Shacter E. Rho GDP dissociation inhibitor protects cancer cells against drug-induced apoptosis. Cancer Res 2005; 65: 6054-62. 